DOI: https://doi.org/10.14232/actahisp.2021.0.37-47

\title{
LA PERCEPCIÓ DELS PATRONS ASCENDENTS EN LES INTERROGATIVES PRONOMINALS DEL CATALÄ ${ }^{*}$
}

\author{
KATA BADITZNÉ PÁLVÖlgyi
}

Universitat Eötvös Loránd de Budapest

\begin{abstract}
Resum: El present estudi investiga mitjançant una enquesta anònima digital la percepció de les preguntes parcials acompanyades d'una entonació ascendent per part de 54 enquestats catalanoparlants nadius, per analitzar fins a quin punt reconeixen l'actidud de l'informant en aquests casos. Segons les nostres hipòtesis, els nadius reconeixeran si la pregunta pronominal ascendent expressa cortesia per part del parlant, o si és una pregunta seguida per un altre enunciat. Els resultats mostren que els nadius reconeixen efectivament si es tracta d'una pregunta pronominal no final, és a dir, seguida per un altre enunciat, però l'entonació ascendent sembla ser insuficient per indicar que la pregunta parcial és cortesa o no.
\end{abstract}

Paraules clau: entonació, pregunta pronominal, cortesia, català, ascendent.

\begin{abstract}
The present study investigates the perception of wh-questions accompanied by a rising intonation by 54 native Catalan-speaking informants through an anonymous digital survey, to analyze the extent to which they recognize the speaker's attitude in these cases. According to our hypotheses, native listeners will recognize whether the rising wh-question expresses politeness on the part of the speaker, or whether it is a question followed by another utterance (that is, non-final). The results show that native speakers of Catalan effectively recognize whether it is a non-final wh-question, but the rising intonation seems to be insufficient to indicate that the wh-question is polite.
\end{abstract}

Keywords: Intonation, Wh-question, Politeness, Catalan, Rising.

\section{Introducció}

Sobre l'entonació de les preguntes pronominals en el català no existeixen gaires treballs (vegeu Bonet (1984, 1986), Salcioli (1988) i el subapartat de Prieto (2002), tots esmentats a Font-Rotchés 2009: 41). El punt comú en aquestes aportacions és que parteixen d'un corpus llegit (per tant, no espontani). L'Atles interactiu de l'entonació del català (Prieto - Cabré (coords.), 2007-2012) ja exposa exemples de parla semiespontània (mitjançant activitats de "map task"). Font-Rotchés (2009) analitza en el seu article 53 preguntes pronominals del català, totes espontànies. Segons aquestes fonts i les nostres pròpies investigacions, trobem melodies tant descendents com ascendents en les interrogatives parcials del català.

\footnotetext{
* Estudi presentat en el Xè Workshop sobre la prosòdia de Català 28 de juny de 2018, ampliat per al present tom.
} 
La percepció dels patrons ascendents en les interrogatives pronominals del català

Segons el principi Peshkovski, com més s'assenyala una distinció per recursos sintàctics, tant menys s'assenyala amb l'entonació (Peshkovski, 1959). Sabem que en diverses llengües l'ordre de paraules en una interrogativa absoluta neutra pot coincidir amb l'ordre de paraules d'una declarativa (p. ex. en el català, "Demà vindrà en Joan." vs. "Demà vindrà, en Joan?"). Així no és estrany que en la majoria de les llengües hi hagi una entonació diferent emprada en cas de les declaratives i interrogatives absolutes, però una entonació coincident en cas de les declaratives i les interrogatives parcials. Com que en les interrogatives parcials la naturalesa de la pregunta s'indica mitjançant el pronom interrogatiu (p. ex. "Quan vindrà en Joan?”), l'entonació ja no ha de jugar un paper important per distingir l'enunciat d'una declarativa, tots dos poden ser acompanyats per la mateixa melodia descendent.

L'ús de la melodia ascendent en les interrogatives parcials del català sembla estar motivat per algun factor, generalment extralingüístic. Podríem enumerar, doncs, els següents contextos que provoquen la utilització de patrons ascendents en les interrogatives pronominals del català:

De tipus neutre, quan la pregunta forma part d'una enumeració (o, segons les nostres observacions, simplement si li segueix un altre enunciat després); quan és una pregunta que es troba a la fi de l'enunciat com un element perifèric en alguns dialectes (com per exemple, en el balear). Pel que fa a les interrogatives parcials no neutres, les preguntes imperatives, exhortatives, exclamatives (de sorpresa) i les retòriques també es poden acompanyar d'una melodia ascendent. A més, és interessant notar que, tal com en el cas del castellà (Alcina - Blecua, 1975: 478; Seco, 1980: 67), les preguntes pronominals corteses-que expressen un interès extra per part del parlant per conèixer la resposta - també es produeixen amb una melodia final ascendent.

Per veure com perceben aquestes preguntes pronominals ascendents els parlants nadius, hem realitzat una enquesta anònima amb 54 informants catalanoparlants, investigant les següents hipòtesis:

(1) Els parlants nadius reconeixeran les preguntes pronominals corteses per la seva melodia ascendent;

(2) Els parlants nadius reconeixeran les preguntes pronominals no finals per la seva melodia ascendent.

En els següents apartats, donarem a conèixer les característiques del corpus, de la metodologia emprada, de l'enquesta, i finalment, els resultats amb unes consideracions posteriors.

\section{Corpus i metodologia}

La tasca dels enquestats va ser escoltar vuit preguntes pronominals (totes produïdes per parlants del català, de fragments televisius extrets de YouTube, per tant, interrogatives espontànies). D'entre les vuit interrogatives, quatre eren ascendents i quatre, descendents. 
Després d'escoltar-les, els enquestats havien de respondre diverses preguntes sobre els enunciats que presentarem en l'apartat 3.

El primer bloc contenia les següents preguntes (totes ascendents):

1) Per (a) quanta gent? (informació oblidada, cortès + no final)

2) Quin temps té? (informació oblidada, cortès)

3) Com estàs? (cortès)

4) Quin és el millor moment? (no final)

El segon bloc contenia preguntes amb entonació descendent, preguntes parcials neutres:

5) I quins poders tens, exactament?

6) Què passa?

7) Com estàs?

8) Com estàs?

Els parlants eren els següents: Helena García Melero, de Barcelona (pregunta 1), Núria Roca, de València (preguntes 2-4.), Raül Ferré, de Barcelona (preguntes 5, 8.) i Ricard Ustrell, de Barcelona (preguntes 6-7).

Al triar els enunciats, hem seguit la metodologia elaborada per Cantero - FontRotchés (2009): sense representar les variacions micromelòdiques no significatives, estandarditzem les melodies per veure si a la fi de l'enunciat es presenta un ascens o un descens. Pel que fa a l'ascens, hem triat enunciats amb un $10 \%$ d'ascens final com a mínim (ja que una diferència tonal de 10\% com a mínim és el llindar de percepció humana, vegeu Kassai, 1998: 213; Mateo - Font-Rotchés, 2011: 1113).

El procés de l'estandardització melòdica es presenta detalladament en Cantero Font-Rotchés (2009). El primer pas és registrar els valors de la freqüència fonamental (F0) característics de cada síl·laba, mitjançant un programa d'análisi acústic com Praat (Boersma - Weenink, 2020). Aquest valor es pren a meitat del nucli sil·làbic (que és generalment una vocal, però en determinats casos pot ser fins i tot una nasal, lateral o vibrant, vegeu Cantero - Font-Rotchés, 2020: 27). En cas de haver-hi una diferència tonal superior a $10 \%$ al dedins de la síl·laba, es prenen els valors extrems (els valors mínim i màxim del canvi tonal).

Després, a cada valor absolut se li atribueix un valor relatiu, depenent del percentatge d'ascens / descens en la melodia experimentat en comparació amb el valor de la síl·laba anterior. El valor del primer segment és l'arbitrari 100 (un nombre fàcil de manejar), i els següents depenen d'aquest valor, són creixents respecte a aquest si la melodia ascendeix a la següent síl·laba, i decreixents si aquesta descendeix. Per il·lustrar el procés, a la Figura 1 presentem el gràfic i la fitxa que vam preparar en cas de cada pregunta (Hz vol dir Hertzs, Perc. és Percentatge, C. Est. és la Corba Estàndard, la _ 
La percepció dels patrons ascendents en les interrogatives pronominals del català

entre vocals vol dir que es produeix un allargament dins de la síllaba i el moviment melòdic caracteritza tots dos segments):

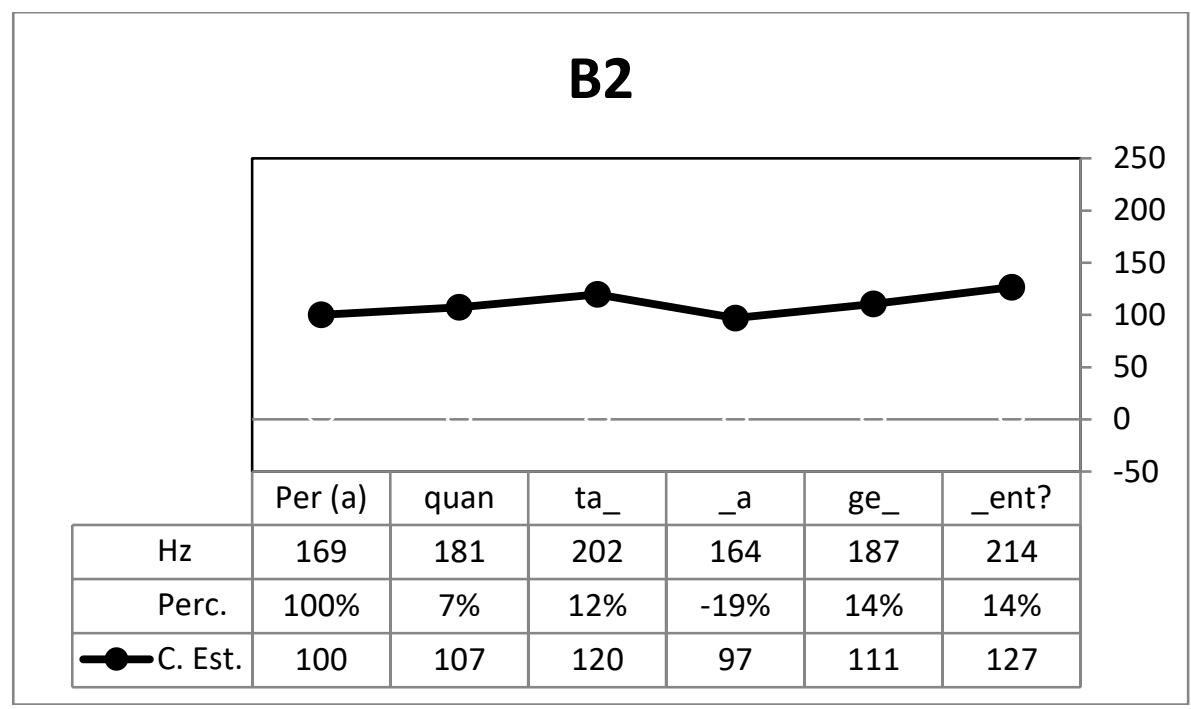

\begin{tabular}{|c|c|c|c|}
\hline \multicolumn{4}{|l|}{ Codi: B2 } \\
\hline \multicolumn{4}{|c|}{ Enunciat: Per (a) quanta gent? } \\
\hline $\begin{array}{l}\text { Localització: } \\
1: 27\end{array}$ & \multicolumn{2}{|c|}{ Programa: Els Matins - Les claus per tenir èxit a YouTube } & $\begin{array}{l}\text { gènere: } \\
\text { entrevista }\end{array}$ \\
\hline $\begin{array}{l}\text { Emissió: } \\
\text { 30/04/2014 }\end{array}$ & \multicolumn{2}{|c|}{ Enllaç: https://www.youtube.com/watch?v=uvJJXgyY_zw } & $\begin{array}{l}\text { Franja: } \\
\text { matinal }\end{array}$ \\
\hline \multicolumn{4}{|c|}{$\begin{array}{l}\text { Decripció de l'informante: Helena García Melero } \\
\text { Sexe: D Edat: } 46 \text { años Professió: Periodista Varietat dialectal: central }\end{array}$} \\
\hline \multirow{2}{*}{\multicolumn{2}{|c|}{ Descripció del context: }} & \multicolumn{2}{|c|}{ Una pregunta repetitiva (informació oblidada), cortés + no final } \\
\hline Patró: & & \multicolumn{2}{|c|}{ II } \\
\hline
\end{tabular}

Figura 1. Gràfic i fitxa dels enunciats, exemple

Com es desprèn del gràfic, aquesta pregunta cortesa acaba amb un ascens de 164 hertzs a 214 hertzs, el que equivaldria a una diferència tonal del 30,49\%, un ascens no tan marcat. Segons la categorització de Font-Rotchés (2007: 133), es tracta del patró entonatiu 2, un patró no marcat, amb ascens final d'entre 10\% i 80\%, i el primer pic en la primera síl·laba tònica, que s'utilitza per una gran varietat d'enunciats, entre d'altres preguntes parcials de reiteració, per exemple.

Segons les hipòtesis, els entrevistats catalanoparlants reconeixeran els enunciats cortesos i suspesos per la melodia final ascendent, és a dir, per la inflexió final ascendent. En el nostre corpus, les primeres quatre preguntes eren ascendents i les 
segones quatre, descendents, pertanyents en total a tres patrons melòdics diferents. Ara veurem quins patrons melòdics catalans representen les preguntes exactament.

L'estructura del contorn melòdic, segons Cantero - Font-Rotchés (2007), es configura a força de tres unitats: l'anacrusi és la primera part del el contorn que dura des del primer segment fins al primer pic (generalment coincident aquest últim amb el primer accent lèxic); des del primer pic trobem el cos (en declinació) fins a l'últim accent lèxic, anomenat nucli, que al mateix temps inicia el tercer bloc, la inflexió final (IF), vegeu la Figura 2:

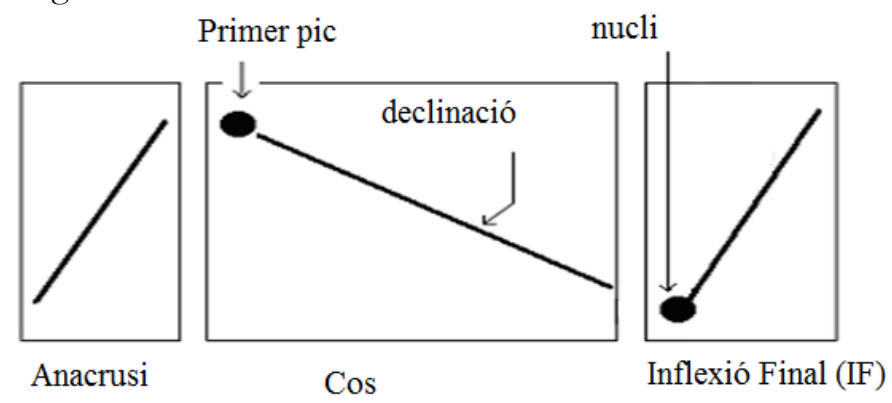

Figura 2. Estructura del contorn melòdic, segons Cantero - Font-Rotchés (2007)

En el primer bloc del nostre experiment, tres de les preguntes ascendents van representar el patró melòdic 2 (Font-Rotchés, 2007: 133), i una, el patró melòdic 3 (Font-Rotchés, 2007: 151). Vegem les característiques de cada un dels dos patrons.

El patró 2 (Fig. 3) es caracteritza per un anacrusi (opcional) d'ascens fins al primer pic d'un $40 \%$ com a màxim, i el primer pic és a la primera vocal tònica del contorn, el punt més alt de la melodia. El cos és en declinació suau i constant. La IF constitueix en si el punt melòdic més baix de la melodia, d'on s'inicia un ascens d'un 10\% a un $80 \%$.

El patró 3 (Fig. 4) difereix del patró 2 només a la inflexió final: és el punt melòdic més baix de la melodia, d'on s'inicia un ascens igual o superior a un $80 \%$ fins a un màxim del 140\%, que culmina en el punt més alt de la melodia.

La corba melòdica esquemàtica dels dos patrons coincideix, la diferència rau en la magnitud del moviment tonal de la inflexió final, fins a 80\% en el cas del patró 2 i igual o superior a aquest valor en cas del patró 3 . 
La percepció dels patrons ascendents en les interrogatives pronominals del català

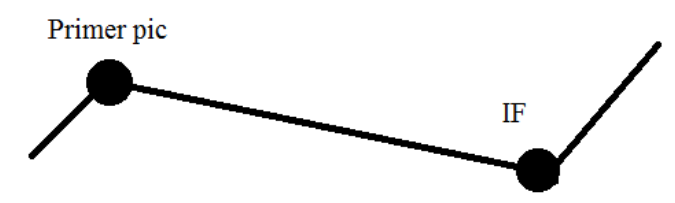

Figura 3. Representació esquemàtica del patró melòdic 2 (Font-Rotchés, 2007: 133)

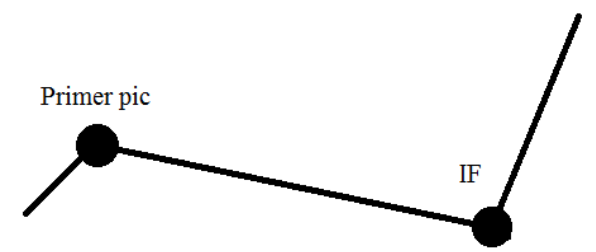

Figura 4. Representació esquemàtica del patró melòdic 3 (Font-Rotchés, 2007: 151)

Des del punt de vista fonològic, el patró 2 expressa el caràcter no acabat de l'enunciat, és un contorn suspès. Això vol dir que els oients, en escoltar la melodia del patró 2 però sense necessàriament entendre l'enunciat ho reconeixen com a suspès, no acabat. El patró 3, però, ja no és suspès, és interrogatiu fonològicament, ja que els oients descodifiquen els enunciats amb aquesta melodia com a preguntes. Els contorns del patró 2 poden ser enunciats declaratius no finals, és a dir, quan el parlant vol indicar amb l'ascens final que desitja continuar mantenint el torn, interrogatius i exclamatius (Font-Rotchés 2007: 133), mentre que els contorns del patró 3 solen ser interrogatius (Font-Rotchés 2007: 152).

El segon bloc de l'experiment contenia 4 preguntes amb entonació descendent, preguntes parcials neutres. Totes pertanyien al patró melòdic 1, reconegut per FontRotchés (2007: 110):

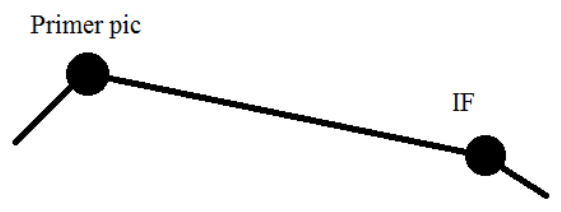

Figura 5. Representació esquemàtica del patró melòdic 1 (Font-Rotchés, 2007: 110)

Aquest patró es caracteritza per un anacrusi (opcional) d'ascens fins al primer pic d'un $40 \%$ com a màxim, el primer pic a la primera vocal tònica del contorn, trobant-se en el punt més alt de la melodia; un cos en declinació suau i constant, i una IF amb descens fins a un $40 \%$ o un ascens fins a un 10\%, culminant-se en el punt melòdic més 
baix. Podem veure, doncs, que aquest patró també es pot acompanyar d'un ascens, per tant, no és necessàriament descendent, però tal ascens no pot sobrepassar el llindar de percepció $(10 \%)$.

Òbviament, aquestes melodies poden acompanyar molts tipus d'enunciats en la realitat. El patró 1 pot acompanyar enunciats declaratius, exclamatius i preguntes que en el seu context se sobreentenen que són preguntes (Font-Rotchés, 2007: 111). En el nostre cas, s'utilitza en les preguntes pronominals neutres, ja que el pronom interrogatiu assenyala la naturalesa de la pregunta i la l'entonació ja no ha de jugar cap paper extra a indicar que l'enunciat és interrogatiu.

La Taula 1 conté tota la informació sobre els patrons melòdics empleats en els 8 enunciats:

\begin{tabular}{|l|l|}
\hline Pregunta & Patró melòdic \\
\hline 1. Per (a) quanta gent? & 2 (ascendent d'entre 10 i $80 \%$ ) \\
\hline 2. Quin temps té? & 3 (ascendent superior o igual a $80 \%$ ) \\
\hline 3. Com estàs? & 2 (ascendent d'entre 10 i $80 \%$ ) \\
\hline 4. Quin és el millor moment? & 2 (ascendent d'entre 10 i $80 \%)$ \\
\hline 5. I quins poders tens exactament? & 1 (descendent) \\
\hline 6. Què passa? & 1 (descendent) \\
\hline 7. Com estàs? & 1 (descendent) \\
\hline 8. Com estàs? & 1 (descendent) \\
\hline
\end{tabular}

Taula 1. Els patrons melòdics de les preguntes

Ja hem vist que l'ascens del patró 2 s'associa a la "no finalitat" de l'enunciat, però tant la melodia ascendent suspesa (del patró català 2) com la melodia ascendent interrogativa (del patró català 3) han estat reconegudes com a trets melòdics de cortesia per Devís (2020). En aquest estudi veurem si els trets melòdics d'ascens esmentats es reconeixen ambdós com a marques de "no finalitat" i de cortesia pels oients.

\section{L'enquesta}

A la primera part de l'enquesta es va demanar als enquestats les seves dades personals. La major part dels enquestats se situa a la franja d'edat d'entre 24 i 50 anys, procedeix de Catalunya i parla la varietat central del català. L'enquesta la van emplenar homes i dones en la mateixa proporció. Les dades es visualitzen en la Taula 2. 
La percepció dels patrons ascendents en les interrogatives pronominals del català

\begin{tabular}{|l|l|l|}
\hline Característiques & $\mathbf{\%}$ \\
\hline Edat (anys) & menys de 18 & 0 \\
\cline { 2 - 3 } & entre 18 i 23 & 11.1 \\
\cline { 2 - 3 } & entre 24 i 35 & $\mathbf{2 9 . 6}$ \\
\cline { 2 - 3 } & entre 36 i 50 & $\mathbf{3 5 . 2}$ \\
\cline { 2 - 3 } & entre 51 i 60 & 14.8 \\
\cline { 2 - 3 } & més de 60 & 9.3 \\
\hline Sexe & home & 50 \\
\cline { 2 - 3 } & dona & 50 \\
\hline procedència & Catalunya & $\mathbf{8 8 . 9}$ \\
\cline { 2 - 3 } & València & 5.6 \\
\cline { 2 - 3 } & Les Illes Balears & 3.7 \\
\cline { 2 - 3 } & Andorra & 0 \\
\cline { 2 - 3 } & altra & 1.9 \\
\hline català nord-occidental & 7.4 \\
\cline { 2 - 3 } & català septentrional & 1.9 \\
\cline { 2 - 3 } & català central & $\mathbf{7 9 . 6}$ \\
\cline { 2 - 3 } & valencià & 7.4 \\
\cline { 2 - 3 } & alguerès & 0 \\
\cline { 2 - 3 } & balear & 3.7 \\
\cline { 2 - 3 } & altre & 0 \\
\hline
\end{tabular}

Taula 2. Dades dels enquestats

La segona part de l'enquesta va oferir les vuit mostres autèntiques (totes extretes d'àudios descarregats de YouTube) que eren totes preguntes pronominals (vegeu l'apartat 2.). Els enquestats, després d'escoltar les preguntes, van haver de decidir si l'enunciat escoltat és una interrogativa cortesa, si serà seguida per un altre enunciat, si és una pregunta emfàtica, de sorpresa, o si és representant d'un dialecte diferent que el de l'enquestat. A continuació presentarem els resultats relacionats amb les nostres dues hipòtesis, enfocant-nos en les primeres dues preguntes que van rebre els enquestats sobre els enunciats.

\section{Resultats}

Com es desprèn de la Taula 3 , en cas de decidir si les preguntes eren corteses o no al context, no hi ha una unanimitat entre les opinions. Una de les preguntes corteses no es reconeix com a tal pels enquestats (la pregunta 1 es considera cortesa només pel $37 \%$ d'ells), mentre que una pregunta amb melodia descendent, la pregunta 7 es reconeix com a cortesa, mentre que en realitat no ho era. No obstant això, les dues interrogatives parcials amb final ascendent (les preguntes 1 i 4) que són seguides per un altre enunciat - per tant, no són finals- es reconeixen com a "no finals" per la majoria dels enquestats. 


\begin{tabular}{|c|c|c|c|c|}
\hline & $\begin{array}{l}\text { entonació de } \\
\text { la pregunta }\end{array}$ & tipus de pregunta & $\begin{array}{l}\text { És una } \\
\text { pregunta } \\
\text { cortesa? }\end{array}$ & $\begin{array}{l}\text { El parlant } \\
\text { seguirà amb un } \\
\text { altre enunciat? }\end{array}$ \\
\hline 1. & \multirow[t]{4}{*}{ ascendents } & $\begin{array}{l}\text { informació oblidada, cortès } \\
+ \text { no final }\end{array}$ & $37 \%$ & $72.2 \%$ \\
\hline 2. & & información oblidada, cortès & $63 \%$ & $24.1 \%$ \\
\hline 3. & & cortès & $88.9 \%$ & $38.9 \%$ \\
\hline 4. & & no final & $37 \%$ & $79.6 \%$ \\
\hline 5. & \multirow[t]{4}{*}{ descendents } & neutre & $29.6 \%$ & $16.7 \%$ \\
\hline 6. & & neutre & $7.4 \%$ & $53.4 \%$ \\
\hline 7. & & neutre & $81.5 \%$ & $48.1 \%$ \\
\hline 8. & & neutre & $35.2 \%$ & $35.2 \%$ \\
\hline
\end{tabular}

Taula 3. Resultats de l'enquesta

Els resultats semblen suggerir que els informants reconeixen bé la motivació d'usar una melodia ascendent en el cas de les preguntes pronominals que seran seguides per un altre enunciat aviat (i per tant es poden considerar "no finals", suspeses), però encerten en menor grau si es tracta d'una altra raó, per exemple la cortesia.

\section{Conclusions}

En aquest estudi ens vam enfocar en la percepció de les interrogatives pronominals del català que van acompanyades d'una melodia ascendent. Desitjàvem investigar fins a quin punt els nadius reconeixen la naturalesa suspesa (és a dir, no final) i cortesa de les preguntes, mitjançant una enquesta digital dirigida a 54 catalanoparlants.

Els nostres resultats permeten suposar que per reconèixer una interrogativa parcial com a cortesa, no és suficient l'ús d'una melodia ascendent, sinó que calen altres claus lingüístiques o fins i tot extralingüístiques (per exemple, l'ús de certes estructures gramaticals, lèxic específic, morfemes típics com els diminutius, i la gestualitat, per exemple els ulls més oberts del que és normal). Això de nou ens pot corroborar l'observació que l'entonació — tot i que la informació lèxica està disponible-no és capaç d'expressar (sense cap altra informació extralingüística, com la gestualitat, per exemple) més que tres característiques: si l'enunciat és emfàtic, suspès o interrogatiu (Cantero, 2002).

Per garantir resultats encara més objectius, es podria repetir la investigació amb preguntes que acabin totes en una síllaba tònica, assegurant així que la corba entonativa es desenvolupa de la mateixa manera sobre la paraula (Prieto, comunicació personal; en cas del castellà, vegeu Cantero, 2002: 89). En el nostre cas, la pregunta 6 no complia amb aquest requisit. També sorgeix l'opció de no treballar amb enunciats reals, sinó només amb parells de còpies del mateix enunciat, en què una còpia és l'original, l'altra és la manipulada, una d'elles és ascendent i l'altra, descendent, però usant el mateix 
La percepció dels patrons ascendents en les interrogatives pronominals del català

enunciat per part del parlant. D'aquesta manera es podrien excloure tots els factors extralingüístics a l'hora del judici de la prova perceptiva. Òbviament, es podria ampliar el nombre d'enquestats o incloure parlants d'altres dialectes per matisar més els resultats obtinguts.

\section{Referències bibliogràfiques}

Alcina Franch, Juan - Blecua, José Manuel (1975). Gramática española. Barcelona: Ariel. Boersma, Paul - Weenink, David (2020). Praat: doing phonetics by computer [Computer program]. Versió 6.1.16, assequible a: https://www.fon.hum.uva.nl/praat/. Darrera consulta: 21-06-2020.

Bonet, Eulàlia (1986). L'entonació de les formes interrogatives en barceloní. Els Marges, 33. 103-117.

Bonet, Eulàlia (1984). Aproximació a l'entonació del català. Tesi de llicenciatura. Universitat Autònoma de Barcelona.

Cantero Serena, Franciso José (2002).Teoría y análisis de la entonación. Barcelona: Ed. Universitat de Barcelona.

Cantero Serena, Francisco José - Font-Rotchés, Dolors (2020). Melodic Analysis of Speech (MAS). Phonetics of Intonation. Dins: Abasolo, Juan - de Pablo, Irati - Ensunza, Ariane (eds.). Contributions on education. Bilbao: Universidad del País Vasco. 20-47.

Cantero Serena, Franciso José - Font-Rotchés, Dolors (2009). Protocolo para el análisis melódico del habla. Estudios de Fonética Experimental, 18. 17-32.

Cantero Serena, Franciso José - Font-Rotchés, Dolors (2007). Entonación del español peninsular en habla espontánea: patrones melódicos y márgenes de dispersión. Moenia, 13. 69-92.

Devís Herraiz, Empar (2020). La entonación de (des)cortesía en catalán. Phonica, 16. 54-82.

Font-Rotchés, Dolors (2009). Les interrogatives pronominals del català central. Anàlisi melòdica i patrons entonatius. Els Marges, 87. 41-64.

Font-Rotchés, Dolors (2007). L'entonació del català. Barcelona: Publicacions de l'Abadia de Montserrat.

Font-Rotchés, Dolors - Mateo Ruiz, Miguel (2011). Absolute interrogatives in Spanish: a new melodic pattern. Anais do VII congresso internacional da ABRALIN. Curitiba (Brasil). 1111-1125.

Kassai, Ilona (1998). Fonetika. [Fonètica]. Budapest: Nemzeti Tankönyvkiadó.

Peshkovskij, Alexander (1959). Intonacija i grammatika. Į̧rannye trudy. Moskva: Uchpedgiz. 
Prieto, Pilar (2002). Entonació. Dins: Solà, Joan (dir.). Gramàtica del català contemporani, vol. 1. Barcelona: Empúries. 393-462.

Prieto, Pilar - Cabré, Teresa (coords.) (2007-2012). Atles interactiu de l'entonació del català. Assequible a: http://prosodia.upf.edu/atlesentonacio/. Darrera consulta: 03-01-2021.

Salcioli, Valeria (1988). Estudio fonético-experimental de la entonación interrogativa catalana. Estudios de Fonética Experimental, 3. 35-70.

Seco, Manuel (1980). Gramática esencial del español. Introducción al estudio de la lengua. Madrid: Aguilar. 